\title{
Amino acid depleted carbonaceous chondrites (C2) from Antarctica
}

\author{
AKira Shimoyama and KaOru Harada \\ Department of Chemistry, University of Tsukuba, Sakura-mura, Ibaraki 305 Japan
}

(Received May 14, 1984: Accepted July 11, 1984)

\begin{abstract}
Amino acids found in two carbonaceous chondrites (C2) from Antarctica, namely the Yamato-793321 and the Belgica-7904, were at the level of sub-namo moles per gram sample. These quantities are very small for $\mathrm{C} 2$ chondrites. The carbon and nitrogen contents of these two meteorites were suitable for $\mathrm{C} 2$ chondrites and, therefore, those two chondrites were unusually depleted in amino acids. This finding is new and there are two plausible explanations for the depletion. One is low temperature and/or aqueous metamorphisms of the two meteorites on their parent bodies, and the other is leaching of water extractable portions of the two meteorites by Antarctic water.
\end{abstract}

\section{INTRODUCTION}

Organic compounds of carbonaceous chondrites were formed abiotically in the early solar system. Stuides of these organic compounds were reviewed most recently by SHIMOYAMA and HARAdA (1982). KVENVOLdEN et al. (1970) reported the first unambiguous evidence of organic compounds indigenous to meteorites for amino acids, examining the Murchison meteorite (C2 chondrite) that fell in Australia in 1969. Thereafter, indigenous amino acids have been found in several carbonaceous chondrites. Generally, C1 and C2 chondrites are known to contain readily detectable amounts of indigenous amino acids. Whereas, C3 and C4 chondrites contain very small amounts of indigenous amino acids and, therefore, there is only one report (HARADA and HARE, 1980, with the Allende) that confirmed amino acids in these types of carbonaceous chondrites.

Recent discovery of a large number of meteorites in Antarctica provided further opportunities to study organic compounds of carbonaceous chondrites. Up to the present, three carbonaceous chondrites from Antarctica were examined for amino acids. Two C2 chondrites revealed amino acids of meteoritic origin whose abundances were comparable to those of the Murchison meteorite. The two chondrites were the Yamato-74662 (Shimoyama et al., 1979a; 1979b) and the Allan Hills-77306 (CRONIN et al., 1979; Kotra et al., 1979). The third carbonaceous chondrite was the Allan Hills-77307 (C3) which did not yield indigenous amino acids (MOORE et al., 1981).

We analyzed, for amino acids, two $\mathrm{C} 2$ chondrites from Antarctica, the Yamato-793321 and the Belgica-7904. Our results shows that both of the two chondrites are unexpectedly depleted in amino acids for $\mathrm{C} 2$ chondrites. In this report we describe our result and discuss possible reasons for the depletion.

\section{SAMPLES}

The meteorite samples we analyzed were supplied by the National Institute of Polar Research of Japan. These samples were the Yamato-793321,4, an exterior portion, and $-793321,5$, an interior portion, of the Yamato793321(Y-793321) meteorite, and the Belgica7904,2, an exterior portion, and -7904,3, an interior portion of the Belgica-7904(B-7904) meteorite. The two meteorites were processed to separate the exterior and interior portions which were wrapped individually with teflon sheet and placed in aluminum containers. These sample processings were carried out in a clean room at the Johnson Space Center, Houston 
(K. YANAI, person. com). The weight of each portion was about four grams.

\section{ANALYSES}

The teflon bags were opened on a clean bench set in our clean room and each portion of the meteorite samples was powdered. One gram each of powdered portions was used for amino acid analyses. Each sample was extracted with water by refluxing. The water solution was dried and then hydrolyzed with $6 \mathrm{M} \mathrm{HCl}$ by refluxing. A fraction of the hydrolyzed solution was dried and taken up with an appropriate volume of $0.01 \mathrm{M} \mathrm{HCl}$. This solution was analyzed quantitatively by a Durrum-500 amino acid analyzer equipped with a fluorescent detector. The other fraction of the hydrolyzed solution was dried and the residue was treated with isopropanol-1.5 $\mathrm{M} \mathrm{HCl}$, and then with TFAA (trifluoroacetic anhydride) $/ \mathrm{CH}_{2} \mathrm{Cl}_{2}$. The N-TFA-isopropyl esters of amino acids, thus prepared, were analyzed for D,L-amino acids by a gas chromatograph equipped with a ChirasilVal glass capillary column $(25 \mathrm{~m})$ and a nitrogenphosphorus detector.

The exterior and interior portions of the two meteorites were processed in parallel along with a procedural blank sample. All processes were carried out in the clean room except for instrumental analyses. The procelain mortar and pestle for powdering samples, and all glassware used for analyses were heated at $450^{\circ} \mathrm{C}$ overnight prior to use. Water used was deionized and distilled twice in the clean room. Hydrochloric acid solution was prepared mixing equal volumes of clean water obtained above and conc. hydrochloric acid, and distilled twice. Organic solvents used were redistilled except for TFAA which was used without purification.

Total carbon and nitrogen analyses were carried out using 3 to $4 \mathrm{mg}$ each of powdered meteorite samples, employing an ordinary method by a CHN analyzer (Perkin Elmer 240). Each analysis was duplicated.

\section{RESUlTS AND Discussion}

Total carbon and initrogen Total carbon and nitrogen contents of the Y-793321 and the B-7904 are shown in Table 1. The Y-793321 shows nearly equal contents of the total carbon and nitrogen in the exterior and interior portions. On the other hand, the B-7904 shows different contents of the two elements in the two portions, indicating a heterogeneous nature of the meteorite. As far as the $\mathrm{C}$ and $\mathrm{N}$ contents are concerned, the two meteorites are not peculiar but ordinary $\mathrm{C} 2$ chondrites (they have been classified also as C2 by KoJima et al., 1984). This ordinary feature is well illustrated by the positions of the two chondrites in the C$\mathrm{N}$ diagram as shown in Fig. 1. In the diagram, the Y-793321 falls in the region typical of C2 chondrites and the B-7904 appears in the region halfway between the $\mathrm{C} 2$ and $\mathrm{C} 3$ chondrites.

Amino acids Amino acid chromatograms obtained at the highest sensitivity of the amino acid analyzer are shown in Fig. 2. All four samples of the meteorite portions show a similar chromatographic pattern which does not differ considerably from that of the procedural blank. Although peaks on the chromatograms are small, they can be assigned to aspartic acid, serine, glycine, alanine and $\beta$-alanine. Approximate estimates of these amino acid quantities are listed in Table 2. These quantities are at most about three times more than those of the procedural blank. Therefore, the amino acids found in the extracts of the meteorite samples contain amino acids introduced during the

Table 1. Carbon and nitrogen contents (\%) of the Y-793321 and the B-7904

\begin{tabular}{cccc}
\hline Samples & & $\mathrm{C}$ & $\mathrm{N}$ \\
\cline { 4 - 4 } Y-793321,4 & & 1.63 & 0.12 \\
Y-793321,5 & 1.68 & 0.11 \\
B-7904,2 & 1.71 & 0.13 \\
& 1.66 & 0.09 \\
B-7904,3 & 1.13 & 0.06 \\
& 1.12 & 0.06 \\
\hline
\end{tabular}

Each analysis was duplicated. 
analysis. Especially, the interior portion of the Y-793321 shows quantities almost the same as those found in the procedural blank, which indicates indigenous amino acids are hardly detected. Therefore, the amounts estimated should be considered to present the upper limits of the amounts of amino acids which might be indigenous to the chondrites. The presence of $\beta$-alanine which is non-proteinous and not common in laboratory and terrestrial contaminants shows that amino acids formed abiotically and indigenous to the meteorites are also recovered, though very small in quantity.

Results of the gas chromatographic analysis are shown in Fig. 3. The exterior sample of the Y-793321 gave the best chromatogram of the four samples. On the chromatogram, roughly equal abundances of D- and L-alanine are observed. In addition, aspartic acid also exhibits D- and L-enantiomers in about equal amounts, although the peaks are very small. Other peaks which evidently correspond to amino acids are glycine and sarcosine, the latter being nonproteinous. Sarcosine was not detected by the amino acid analyzer because its response was very low on the detector. Detection by one method does not necessarily lead to confirmed identification. However, sarcosine is not common in contaminants and its presence in the

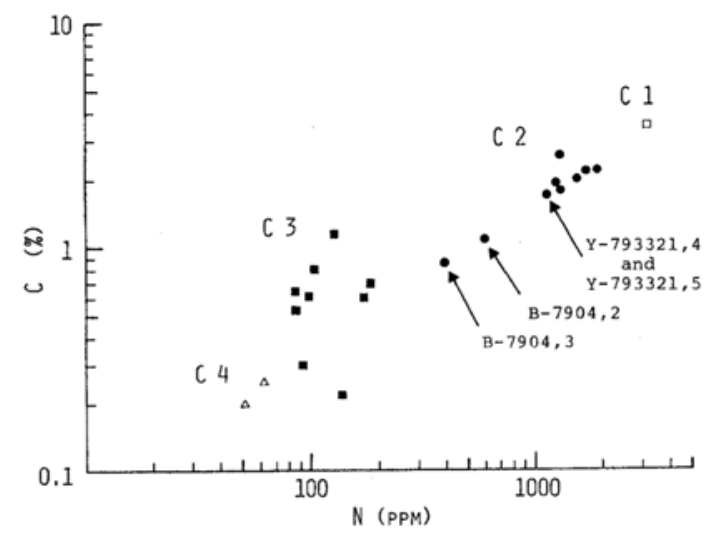

Fig. 1. Carbon and nitrogen contents of the $Y-793321$ and the B-7904 together with those of other carbonaceous chondrites. The $C$ and $N$ contents of the other chondrites are from GIBSON et al. (1971).
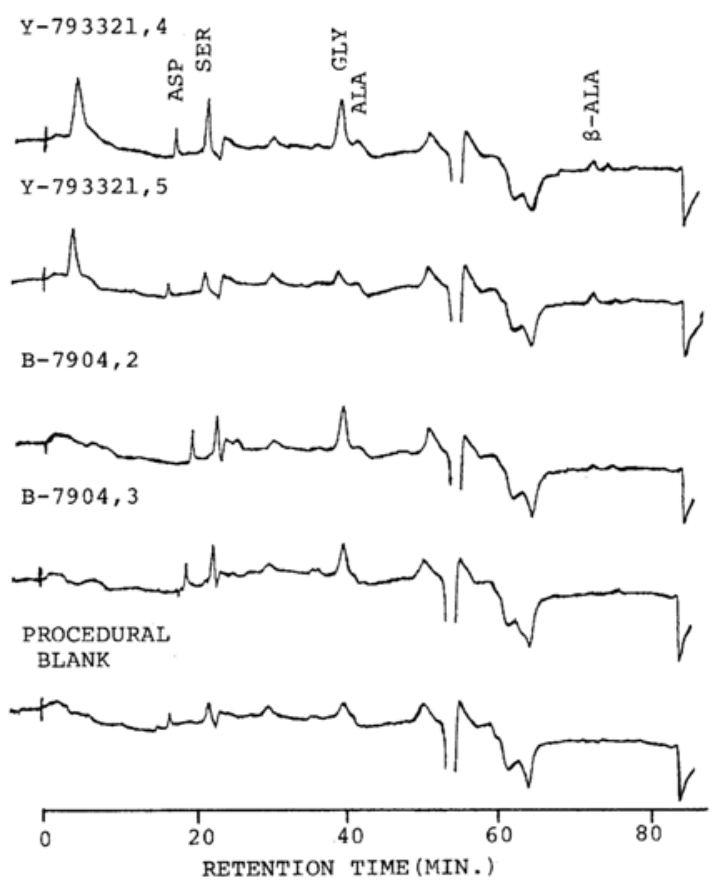

Fig. 2. Amino acid chromatograms of the Y-793321 and the B-7904. Abbreviations: ASP, aspartic acid; SER, serine; GLY, glycine; ALA, alanine; $\beta-A L A, \beta-$ alanine.

meteorites is very likely on the basis of the finding of another nonproteinous amino acid, $\beta$ alanine. On the gas chromatogram a large peak appears at the retention time of $\beta$-alanine. Because the peak is so large, it can not be assigned solely to $\beta$-alanine. Probably, a large part of the peak is due to an unknown compound. About equal abundances of the enantiomers and the presence of non-proteinous beside proteinous amino acids indicate that these amino acids found are abiotic in origin and, therefore, they are indigenous to the meteorite.

On the gas chromatogram of the B-7904, relatively large peaks of the L-enantiomer are observed for alanine and aspartic acid, while the peak of the D-enantiomer of alanine was not found and that of aspartic acid was relatively small. Apparently, proteinous L-amino acids of contaminants are overwhelmingly present on the chromatogram. However, the appearance of sarcosine and D-aspartic acid clearly indicates 
Table 2. Amino acids from the $Y-793321$ and the B-7904 (pmol/g)

\begin{tabular}{|c|c|c|c|c|c|}
\hline Amino acids & $\begin{array}{c}\text { Y793321,4 } \\
\text { exterior } \\
\end{array}$ & $\begin{array}{c}\text { Y793321,5 } \\
\text { interior }\end{array}$ & $\begin{array}{l}\text { B- } 7904,2 \\
\text { exterior } \\
\end{array}$ & $\begin{array}{c}\text { B-7904,3, } \\
\text { interior }\end{array}$ & $\begin{array}{c}\text { Procedural } \\
\text { blank }\end{array}$ \\
\hline Aspartic acid & 170 & 76 & 190 & 150 & 68 \\
\hline Serine & 330 & 110 & 260 & 240 & 130 \\
\hline Glycine & 340 & 90 & 310 & 250 & 100 \\
\hline Alanine & 86 & + & - & 22 & + \\
\hline$\beta$-Alanine & 48 & 48 & 14 & 8 & - \\
\hline
\end{tabular}

$+:$ Detected but too small to estimate.

$-:$ Not detected.

that amino acids indigenous to the meteorite are also present on the chromatogram.

Abundances of amino acids found in carbonaceous chondrites have been known to relate with carbon contents. This relation is seen in the varying trend of amino acid abundances and carbon contents from the Murchison to the Allende meteorites as shown in Table 3. However, the Y-793321 and the B-7904 yielded extremely small quantities of amino acids for their carbon contents. In comparison, both of the two meteorites contain about $1 / 500$ of the amount reported for the Murchison and about $1 / 100$ of that for the Yamato-74662. This low level of amino acid abundance is comparable only to that for the Allende of the $\mathrm{C} 4$ chondrites (we use here the type $\mathrm{C} 4$ for the Allende by GiBSON et al., 1971, according to their carbon analysis, although the meteorite was classified as type III by CLARKE et al., 1970 and C3 by MCSweEN, 1979).

These considerations reveal that the Y793321 and the B-7904 are definitely depleted in amino acids, and show a unique organo chemical distribution that has not been observed with other C2 chondrites previously analyzed for amino acids. From the current experimental results, it is difficult to point out a precise reason for the amino acid depletion of the two C2 chondirtes. However, there are two plausible explanations for the depletion as discussed below.

Low temperature and/or aqueous metamorphisms on parent bodies Alteration states of several carbonaceous chondrites were reported by Kojma et al. (1984). According to their examination of the alteration state of chondrules, the Y-793321 was altered weakly to moderately and the B-7904 moderately. In addition, the ground-masses of the two meteorites were observed to have changed to brown to yellowish brown colored materials. An electron microscopic study on phillosilicates also indicated that the two meteorites had experienced some alteration reactions in aqueous or gasseous phases (AKAI, 1984). If these alterations took place, organic compounds were possibly affected. Generally, a

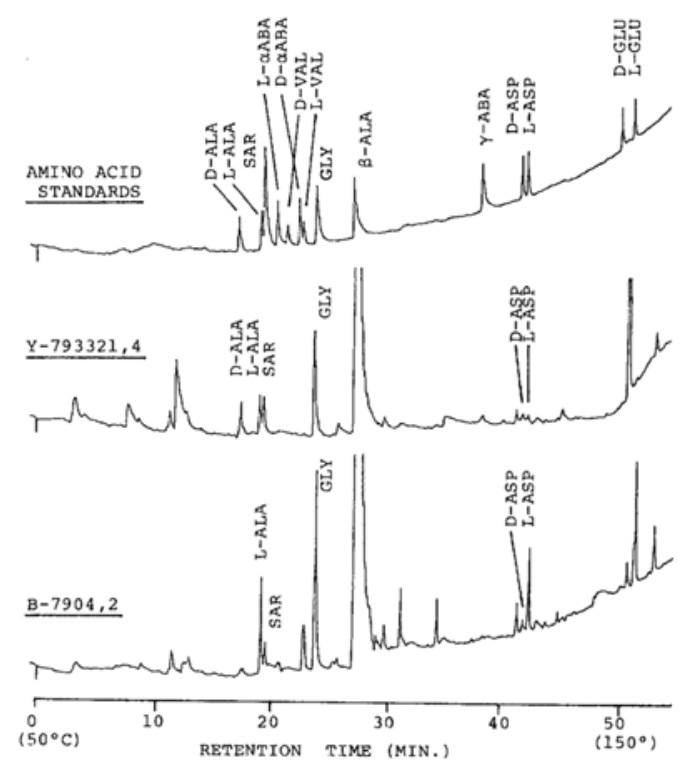

Fig. 3. Gas chromatograms of N-TFA-isopropyl esters of amino acids of the Y-793321,4 and the B-7904,2 as well as of authentic amino acids. Abbreviations: ALA, alanine; $S A R$, sarcosine; $\alpha A B A, \alpha$-amino-n-butyric acid; $V A L$, valine; $G L Y$, glycine; $\beta$-ALA, $\beta$-alanine; $\gamma A B A, \gamma$ aminobutyric acid; $A S P$, aspartic acid; GLU, glutamic acid. 
Table 3. Total carbon and total amino acids from carbonaceous chondrites

\begin{tabular}{|c|c|c|}
\hline Meteorites & $\begin{array}{c}\mathrm{C} \\
(\%)\end{array}$ & $\begin{array}{c}\text { Amino acids } \\
\mathrm{nmol} / \mathrm{g}\end{array}$ \\
\hline Murchison & $2.01^{1)}$ & $397^{3)}$ \\
\hline Y-74662 & $1.51^{2)}$ & $109^{4)}$ \\
\hline ALHA-77306 & $1.32^{2)}$ & $40^{3)}$ \\
\hline Allende & $0.25^{1)}$ & $0.46^{5)}$ \\
\hline Y-793321,4 & 1.66 & 0.97 \\
\hline B- 7904,2 & 1.13 & 0.77 \\
\hline
\end{tabular}

1) GIBSON et al. (1971).

2) GIBSON and YANAI (1979).

3) CRONIN et al. (1979).

4) SHIMOYama et al. $(1979 \mathrm{~b})$.

5) HARADA and HARE (1980).

large portion of organic material of a carbonaceous chondrite exists in insoluble form. Amino acids and their precursors are found in the water extract which accounts for only a small portion of meteoritic organic compounds. A loss of this small portion by alteration probably does not change the contents of carbon and nitrogen significantly. Therefore, the weak to moderate alteration could have been the reason for the amino acid depletion in the two $\mathrm{C} 2$ chondrites.

\section{Leaching by Antarctic water Although the} periods of time for the Y-793321 and the B7904 in Antarctic ice are yet to be known, these periods might have been as long as several thousand to a hundred thousand years. During these periods the two meteorites were surrounded by water molecules of Antarctic ice. The two meteorites stayed later on the surfaces of blue ice for unknown periods of time, where they were often covered with snow. Because carbonaceous chondrites are dark in color, snow covering those chondrites might often have been thawed by the sun light. Therefore, a loss of water-extractable organic compounds due to leaching by water in Antarctic ice and on the blue ice could be another possible reason why the two chondrites are depleted in amino acids. If this leaching is a cause, the process must have been extensive in termes of time, since amino acids are depleted not only in the exterior but also in the interior portions of the two meteorites. Some Antarctic meteorites were found to have been contaminated with terrestrial oxygen as revealed by an oxygen isotope study (ClAyton et al., 1984). The source of the contaminating oxygen is indeed water molecules of Antarctic ice and/or snow. An oxygen isotope study of the two meteorites will probably clarify whether the two meteorites had been extracted with Antarctic water.

In addition, two more points are discussed briefly.

Amino acids might have been formed in nebular processes in very small quantity in the two chondrites in comparison to other $\mathrm{C} 2$ chondrites such as the Murchison and the Yamato-74662. However, as mentioned repeatedly, the $\mathrm{C}$ and $\mathrm{N}$ contents of the Y-793321 and the B-7904 are adequate for C2 chondrites (cf. Fig. 1). This suggests that $\mathrm{C}$ and $\mathrm{N}$ compounds of the two meteorites (or at least the Y-793321) were also primarily formed approximately at the same level of concentration as for the Murchison and the Yamato-74662. Therefore, it is very unlikely that only water extractable organic compounds were selectively formed in such a small quantity as found in the Y-793321 and the B-7904.

Amino acid analyses in this study are similar to those used for the Yamato-74662 in which expectable quantities of amino acids as a $\mathrm{C} 2$ chondrite was found in the water extract. Our analytical result is also supported by a similar result obtained by GiBson et al. (1984) for the two meteorites and the Yamato-791824. Errors in the analytical technique are, thus, ruled out.

\section{CONCLUSION}

The amounts of amino acids estimated in the water extracts of the Y-793321 and the B7904 are not all indigenous to the two carbonaceous chondrites. As a result, the two $\mathrm{C} 2$ chondrites contain extremely small quantities of amino acids. These quantities are about $1 / 500$ of that for the Murchison and about $1 / 100$ of the Yamato-74662. The finding of this kind has not been reported for $\mathrm{C} 2$ chondrites previously analyzed. Low temperature and/or aqueous 
metamorphisms of the two meteorites on their parent bodies might have been a reason for the amino acid depletion. If this is the case, the depletion may give a clue to a better understanding for the primordial organic reactions in the early solar nebula. Since these two chondrites were collected in Antarctica, leaching of water extractable portions of the two chondrites by Antarctic ice(water) may be responsible for the amino acid depletion. If this is the case, the special environment of Antarctica is not suitable for the preservation of the water extractable organic compounds of meteorites. Studies of organic compounds of more Antarctic carbonaceous chondrites are necessary as well as other kinds of studies such as oxygen isotope study that may reveal whether the two chondrites were extracted with water from Antarctic ice.

Acknowledgements-We are grateful to the National Institute of Polar Research of Japan for providing us with the samples of the Yamato-793321 and the Belgica7904 for the analyses of organic compounds. We thank Mr. H. NAKAZONO and Mr. I. IIDA of the Chemical Analysis Center of the University of Tsukuba for the assistance to amino acid analyses and elemental analyses of carbon and nitrogen. This work was partly supported by the Grant in Aid for Scientific Research, No. 58540348 , from the Ministry of Education of Japan.

\section{REFERENCES}

AKAI, J. (1984) Mineralogical characterization of matrix materials in carbonaceous chondrite Yamato793321 and Belgica-7904 by HREM. Abstr. Ninth Symposium on Antarctic Meteorites. 59-61 Natl. Inst. Polar Res., Tokyo.

Clarke, R. S., Jarosewich, E., Mason, B., Nelen, J., . GOMEZ, M. and HYDE, J. R. (1970) The Allende, Mexico, meteorite shower. Smithson. Contrib. Earth Sci. 5, 1-53.

CLAYTON, R. N., MAYEDA, T. K. and YANAI, K. (1984) Oxygen isotopes in Yamato meteorites. Abstr. Ninth Symposium on Antarctic Meteorites. 86-87 Natl. Inst. Polar Res., Tokyo.

Cronin, J. R., Pizzarello, S. and Moore, C. B. (1979) Amino acids in an Antarctic carbonaceous chondrite. Science 206, 335-337.

GibSON, E. K., MoOre, C. B. and Lewis, C. F. (1971) Total nitrogen and carbon abundances in carbonaceous chondrites. Geochim. Cosmochim. Acta 35, 599-604.

GIBSON, E. K. and YANAI, K. (1979) Total sulfur abundances in Antarctic Meteorites. Mem. Natl. Inst. Polar Res. Spec. Issue 15, 189-195.

Gibson, E. K., Cronin, J. R., Kotra, R. K., Primas, T. R. and MOORE, C. B. (1984) Amino acids, carbon and sulfur abundances in Antarctic carbonaceous chondrites. Abstr. Ninth Symposium on Antarctic Meteorites. 78-80 Natl. Inst. Polar Res., Tokyo.

HARADA, K. and HARE, P. E. (1980) Analyses of amino acids from the Allende meteorite. In Biogeochemistry of amino acids. (ed. P. E. HARE, T. C. HOERING and K. KING, JR.), 169-181 John Wiley, New York.

KoJIma, H., IKedA, Y. and YANAI, K. (1984) Classification of the Yamato carbonaceous chondrites. Abstr. Ninth Symposium on Antarctic Meteorites. 22 Natl. Inst. Polar Res., Tokyo.

Kotra, R. K., Shimoyama, A., Ponnamperuma, C. and HARE, P. E. (1979) Amino acids in a carbonaceous chondrite from Antarctica. J. Mol. Evol. 13, 179-184.

Kvenvolden, K., Lawless, J., Pering, K., PeterSON, E., Flores, J., PONNAMPERUaM, C., KAPlan, I. R. and MOORE, C. (1970) Evidence for extraterrestrial amino-acid and hydrocarbons in the Murchison meteorite. Nature 228, 923-926.

MCSWEEN, H. Y. (1979) Are carbonaceous chondrites primitive or processed? Rev. Geophys. Space Phys. 17, 1059-1078.

MoORe, C. B., Cronin, J. R., Pizzarello, S., Ma, M-S. and SCHMitT, R. A. (1981) New analyses of Antarctic carbonaceous chondrites. Mem. Natl. Inst. Polar Res., Spec. Issue 20, 29-32.

Shimoyama, A., Ponnamperuma, C. and Yanai, K. (1989a) Amino acids in the Yamato carbonaceous chondrite from Antarctica. Nature 282, 394-396.

Shimoyama, A., Ponnamperuma, C. and Yanai, $\mathrm{K}$. (1979b) Amino acids in the Yamato-74662 meteorite, an Antarctic carbonaceous chondrite. Mem. Natl. Inst. Polar Res. Spec. Issue 15, 196-205.

Shimoyama, A. and HARADA, K. (1982) Organic compounds of meteorites. Kagaku (Kyoto) 37, 433442 (Japanese). 